\title{
EDUCAÇÃO, TEATRO E INVENÇÃO: ENSAIO PARA UMA PÓS-DRAMATURGIA DO ENCONTRO NA AULA
}

\author{
EDUCATION, THEATER AND INVENTION: TESTING FOR A POST-DRAMATURGY OF ENCOUNTER IN THE
} CLASSROOM

EDUCACIÓN, TEATRO E INVENCIÓN: ENSAYO PARA UNA “PÓS-DRAMATURGIA” DEL ENCUENTRO EN AULAS

FERNANDES, Fabíola Rahde 1

PACHECO, Eduardo Guedes ${ }^{2}$

\section{RESUMO}

O presente estudo investiga de que formas a criação teatral movimenta processos de invenção e resistência à mecanização das práticas na educação escolarizada. Tem por objetivo pesquisar modos de atuação do teatro junto a alunos do sexto ano do ensino básico e toma como cenário uma escola do Litoral Norte do Estado do Rio Grande do Sul. A concepção de plano de composição de Deleuze e Guattari, consoante a considerações de outros pensadores contemporâneos, é evocada com o intuito de discutir, bem como explorar modos de ser e estar na escola. Para isso, a pesquisa busca referência no conceito de pósdramático de Lehmann, tratando-o como operador na invenção da metodologia, denominada pós-dramaturgia do encontro. Conclui, assim, que as experimentações propostas indicam caminhos possíveis de atuação do teatro como prática de criação coletiva no contexto pesquisado.

Palavras-chave: Escola. Teatro. Criação. Drama. Pós-dramático.

\section{ABSTRACT}

This study investigates how the theatrical creation moves processes of invention and resistance to the mechanization of practices in school education. It aims to research ways of acting in theater with students in sixth grade and takes as a scenario a school on the North Coast of the State of Rio Grande do Sul. Deleuze and Guattari's concept of composition plan, along with considerations from other contemporary thinkers, is evoked in order to discuss and explore ways of being in the school place. For this, the research seeks reference in Lehmann's postdramatic concepts, alluding him as an operator in the invention of the methodology called post-dramaturgy of encounter. This research concludes that the proposed experiments indicate possible ways of theater acting as a practice of collective creation in the researched context.

Keywords: School. Theater. Creation. Drama. Postdramatic.

\section{RESUMEN}

El presente estudio busca saber de qué formas la creación teatral promueve procesos de invención y resistencia a la mercantilización de las prácticas en la educación escolarizada. El objetivo principal es investigar modos de actuación teatral junto a los estudiantes del sexto año de la enseñanza primaria y tiene como escenario una escuela del Litoral Norte del Estado del Rio Grande do Sul. El concepto de plan de composición de Deleuze y Guattari, juntamente a las consideraciones de otros teóricos contemporáneos, es evocado con el intuito de discutir y explorar modos de ser y estar en la escuela. A este respecto, la investigación busca referencias en el concepto de pós-dramático de Lehmann, tratándolo como operador en la elaboración metodológica, llamada de pós-dramaturgia do encontro. Por consiguiente, las experimentaciones propuestas muestran los caminos posibles de actuación en el teatro como práctica de creación colectiva el en contexto de la encuesta.

Palabras clave: Escuela. Teatro. Creación. Drama. Pós-dramático.

\footnotetext{
${ }^{1}$ Universidade Estadual do Rio Grande do Sul - UERGS - Osório - RS.

2 Universidade Estadual do Rio Grande do Sul - UERGS - Osório - RS.
} 


\section{INTRODUÇÃO}

Este estudo constitui-se em um desdobramento de pesquisa de mestrado realizada no Programa de Mestrado Profissional em Educação da Universidade Estadual do Rio Grande do Sul, na linha de pesquisa Linguagens e Artes em Contextos Educacionais. O espaço em que a pesquisa prática se situa é uma escola de ensino fundamental localizada no Litoral Norte do Estado do Rio Grande do Sul, lócus em que a pesquisadora atua como professora de teatro. Objetiva-se, nesse contexto, problematizar a aula de teatro no âmbito do ensino básico com alunos do sexto ano do ensino regular, junto dos quais foram propostas práticas de criação teatral em sala de aula.

Para o presente trabalho, são eleitos aspectos referentes aos dezoito encontros que compõem a investigação, sendo tais enfoques escolhidos levando em consideração os momentos que melhor dão conta de problematizar as questões abarcadas na pesquisa. Tais aspectos são discutidos tendo por base um processo educacional para o qual foi utilizado o texto dramático "Sonhos de uma noite de verão", de William Shakespeare, como materialidade disparadora para a criação teatral na aula e também para as problematizações propostas na investigação. Os trajetos da pesquisa são traçados tendo como propulsora a seguinte pergunta suleadora: Como a criação teatral movimenta processos de resistência à mecanização das práticas escolares? Em zona de vizinhança (DELEUZE; GUATTARI, 2010) com essa indagação questiona-se também: Que docência e qual teatro são necessários à produção destes processos?

Sulear articula-se aqui à invenção de modos de existência que singularizam os encontros pedagógicos e potencializam a vida da educação na aula de teatro (CORAZZA, 2013). Significa, de tal modo, forjar uma docência que produz movimentos no encontro educacional, estabelecendo relações pedagógicas à maneira de "um cão que faz seu buraco, um rato faz a sua toca. $\mathrm{E}$, para isso, encontrar seus próprios pontos de subdesenvolvimento, seu próprio patoá, seu próprio terceiro mundo" (DELEUZE; GUATTARI, 1977, p. 28-29).

O Sul, ou terceiro mundo, é visto então como possibilidade de experimentação de devires na aula de teatro, na trilha do que Deleuze chama de constituição de uma consciência de minoria como potencialidade do teatro. A esse respeito, afirma o autor que "devir minoritário é um objetivo, e um objetivo que diz respeito a todo mundo [...] já que cada um constrói sua variação em torno da unidade de medida despótica e escapa, de um modo ou de outro, do sistema que fazia dele uma parte da maioria" (DELEUZE, 2010, p. 63) e, ainda, "se a maioria remete a um modelo de poder - histórico, estrutural ou os dois ao mesmo tempo - é preciso dizer também que todo mundo é minoritário, potencialmente minoritário, na medida em que desvia desse modelo" (DELEUZE, 2010, p. 59, grifo do autor).

Com vistas à exploração da criação teatral como aparato de resistência e produção de devires em aula, este estudo apoia-se na filosofia da diferença elaborada por Gilles Deleuze e Félix Guattari (2010). Para os pensadores, a filosofia, a ciência e a arte são as três grandes formas de pensamento e o que as define é sempre "enfrentar o caos, traçar um plano, esboçar um plano sobre o caos" 
(DELEUZE; GUATTARI, 2010, p. 233). Na perspectiva de que "pensar é criar" os autores operam com a ideia de que o filósofo pensa conceitos ou acontecimentos, traçados em um plano de imanência. $O$ cientista pensa funções ou proposições referenciais, traçadas em um plano de coordenadas, e o artista pensa monumentos ou sensações, traçadas em um plano de composição.

Para Deleuze e Guattari, o mundo é concebido como processo de criação do novo em que o pensamento não exerce um papel de comunicação, descoberta ou reflexão sobre determinada realidade, mas na atividade de invenção desta, por meio da criação de conceitos, de funções ou de sensações. Ainda sobre o pensamento, os autores consideram que:

\begin{abstract}
o que concerne ao pensamento, como tal, deve ser separado dos acidentes que remetem ao cérebro, ou às opiniões históricas. [...] O pensamento reivindica "somente" o movimento que pode ser levado ao infinito. O que o pensamento reivindica de direito, o que ele seleciona, é o movimento infinito ou movimento do infinito. É ele [o movimento] que constitui a imagem do pensamento. [...] o movimento tomou tudo, e não há lugar nenhum para um sujeito e um objeto que não podem ser senão conceitos. (DELEUZE; GUATTARI, 2010, p. 47-48).
\end{abstract}

Inspirado nas ideias dos filósofos supracitados, o estudo se propõe a investigar a sala de aula como um plano de composição. Este configurando-se como um espaço de teatro e, nesse cenário, como espaço de criação e produção de pensamento. As teatralidades são vistas, aqui, como movimentos articuladores de pensamentos criadores que tendem ao infinito. Nesse ponto de vista, o trabalho compreende o espaço de formação da sala de aula como cenário de invenção de teatralidades e de corporeidades, no qual aprender não remete a ações de apropriação de sujeitos sobre objetos, mas de criação de sensações, de invenção de mundos e, portanto, de fabricação de pensamento e produção de vida.

Inserida nesse panorama de criação, a investigação flerta com a ideia de docência artista (CORAZZA, 2013), na medida em que ensaia modos de ser docente que objetivam tanto criar blocos de sensação na aula, quanto planos de invenção de saberes. A respeito das ressonâncias produzidas por Gilles Deleuze no campo da Educação, Corazza nos diz que esse pensador traz "belas, novas e fortes lufadas de enunciação, que nos levam a pensar e a viver a Educação do mesmo modo que um artista pensa e vive a sua arte" (CORAZZA, 2013, p. 18). Nessa perspectiva, traça-se um plano de compartilhamento entre o campo da Educação e a arte teatral, a partir do deslocamento do conceito de pós-dramático (LEHMANN, 2017) para o contexto pesquisado como um operador metodológico (GALLO, 2017), ao mesmo tempo em que se tece um território que concebe o teatro como dispositivo ou aparato de resistência aos poderes que enfraquecem as potências de vida na aula.

\title{
A ESCOLA COMO INVENÇÃO HISTÓRICA
}

A partir de Deleuze, no que concerne à ideia de que a constituição de uma consciência de minoria pode ser forjada nas práticas de desvios dos modelos de poder históricos ou estruturais, este trabalho opta por discutir o modelo de escola vigente em grande parte das instituições de ensino da atualidade e, a partir disso, problematizar os modos de ser e estar docente e discente em um desses espaços, em específico, no contexto da sala de aula (DELEUZE, 2010). A investigação não busca mais do que inventar desvios, lugares de respiro ou patoás (DELEUZE; GUATTARI, 1977), os quais 
produzam deslocamentos que possibilitem a criação teatral ser experimentada como invenção, colocando em cena corporeidades e dizeres inventados na aula. Nesse contexto cabe questionar: De qual modelo de escola se fala aqui?

O modelo de escola, tal como o conhecemos hoje em grande parte das instituições de ensino ocidentais, configura-se, segundo Ruy Canário, como uma invenção histórica que marcou o início da modernidade e se tornou hegemônica. Diante disso, a organização escolar como historicamente a conhecemos "corresponde a modos específicos de organizar os espaços, os tempos e agrupamentos de alunos e as modalidades de relação com o saber" (CANÁRIO, 2005, p. 62). Para o autor,

\begin{abstract}
não há dúvidas que estamos diante de uma invenção histórica, contemporânea da dupla revolução industrial e liberal que baliza o início da modernidade e que introduziu, como novidades, o aparecimento de uma instância educativa especializada que separa o aprender do fazer; a criação de uma relação social inédita, a relação pedagógica no quadro de classe, superando a relação dual entre mestre e aluno; uma nova forma de socialização (escolar) que progressivamente viria a se tornar hegemônica. (CANÁRIO, 2005, p.61).
\end{abstract}

O deslocamento da relação entre professor e aluno para uma relação mediada pelo quadro de classe opera também determinada configuração de espacialidade: salas usualmente quadrangulares, com mesas e cadeiras dispostas em fileiras, direcionando a perspectiva de visão para frente e para o quadro onde, ao lado, normalmente fica a mesa do professor. Essa organização de escola corresponde a uma transição de "modos de ensino individualizados (mestre e um aluno) para modos de ensino simultâneo (um mestre e uma classe)", a qual "viabilizou a emergência dos sistemas escolares modernos" (CANÁRIO, 2005, p. 62).

A escola passa, assim, a ocupar o papel de instituição que funciona como fábrica de cidadãos afirmando, do ponto de vista histórico, um papel de unificação cultural, linguística e política. O que se delineia, portanto, é uma configuração de aula mediada pelo quadro de classe que tende à noção de que o professor deve ministrar a aula para muitos como se estes fossem um, remetendo à ideia de uniformização, ordem, estrutura e regulação de corpos, tempos e vidas na sala de aula. Ao situar as ponderações acima com o contexto deste estudo, pergunta-se: De que formas essa configuração engendra a mecanização das práticas em sala de aula? Que modos de ser e estar na aula esses modelos objetivam forjar?

Com o intuito de pensar tanto as funções da instituição escolar quanto as maneiras pelas quais esse dispositivo produz corpos e subjetividades na atualidade, Paula Sibilia traça um panorama historiográfico e genealógico da escola ao longo dos séculos (SIBILIA, 2012). A autora propõe pensar a escola como uma tecnologia de época e, em consonância com as ideias de Canário, compreende-a como uma instituição "concebida com o objetivo de atender a um conjunto de demandas específicas do projeto histórico que a planejou e procurou pô-la em prática: a modernidade” (SIBILIA, 2012, p. 17). A escola seria assim:

um dispositivo, uma ferramenta, intrincado artefato destinado a produzir algo. E não é muito difícil verificar que, aos poucos, essa aparelhagem vai se tornando incompatíve/ com os corpos e as subjetividades das crianças de hoje. A escola seria, então, uma máquina antiquada. Tanto seus componentes quanto seus modos de funcionamento já não entram facilmente em sintonia com os jovens do século XXI. (SIBILIA, 2012, p. 13, grifo da autora). 
Com esse panorama, a escola se constitui em um aparato, uma tecnologia de época inventada com o objetivo de produzir modos de ser ou subjetividades que respondessem às necessidades do pensamento moderno, no qual milhares de corpos "se mobilizaram ao compasso dos ritmos urbanos e industriais, tutelados pelos vigorosos credos da ciência, da democracia e do capitalismo, rumo a uma meta então considerada indiscutível: o progresso universal" (SIBILIA, 2012, p. 42). As corporeidades seriam forjadas na configuração do espaço-tempo escolar com o objetivo de corresponderem aos imperativos de ordenamento, uniformização e disciplina, comuns também ao "conjunto de 'instituições de confinamento', como as denominou Michel Foucault: do lar aos reformatórios, da fábrica aos quarteis, dos hospitais aos asilos, à prisão e à universidade" (SIBILIA, 2012, p. 43).

A partir das considerações tecidas até aqui, o estudo trabalha com a ideia de que tais imperativos de ordenamento, uniformização e disciplina engendram muitas das mecanizações vivenciadas no espaço escolar, desde os horários reguladores dos inícios e finais de cada período de aula, até as configurações de espacialidade, divisão do currículo entre outras particularidades e normatizações que compõem a rotina escolar. Pode o teatro ser aparato de resistência na desconstrução dessas mecanizações no contexto escolar? Qual teatro seria necessário para tais práticas?

\section{AULA: UM ESPAÇO DRAMÁTICO?}

A palavra drama possui variadas acepções. O Novo Dicionário da Língua Portuguesa a define como "designação genérica de composição dialogada ou teatral; texto ou peça teatral [...] o gênero teatral; teatro [...] série de episódios complicados ou patéticos [...] acontecimento terrível, sinistro; catástrofe" (FERREIRA, 1986, p. 611). No Dicionário de Teatro, Pavis (2008, p. 109) nos diz que o termo drama, do grego ação, designa a obra teatral ou dramática, sendo

\footnotetext{
o teatro dramático (que BRECHT oporá à forma épica) é o da dramaturgia clássica, do realismo e do naturalismo, da peça bem-feita. ele se tornou a forma canônica do teatro ocidental desde e célebre definição de tragédia pela Poética de ARISTÓTELES: "Imitação de uma ação de caráter elevado e completo, de uma certa extensão [...] imitação que é feita pelas personagens em ação e não através de um relato, e que, provocando piedade e terror, opera a purgação própria de tais emoções". (PAVIS, 2008, p. 110 - grifos do autor).
}

Em concordância com as ideias anteriores, Ryngaert refere que o teatro aristotélico designa "uma dramaturgia que invoca Aristóteles e se funda na ilusão de identificação. Esse teatro 'dramático' [...] repousa sobre a coerência e a unificação da ação, em sua construção de um conflito a ser resolvido no desfecho", sendo que, no âmbito da dramaturgia clássica, são três as unidades que compõem o texto dramático: ação, lugar/espaço e tempo (RYNGAERT, 2013, p. 224). Entre as três, a unidade de ação é considerada imprescindível, visto que abrange a estrutura dramática inteira.

Logo, a ação é considerada una ou unificada quando toda a narrativa se estrutura ao redor de uma história principal. A unidade de lugar compreende o uso de um só espaço, o qual o espectador seja capaz de atingir com o olhar, embora subdivisões desse lugar sejam possíveis. Os preceitos da unidade de tempo exigem que a ação da peça não ultrapasse vinte e quatro horas (PAVIS, 2008) e, 
desse modo, a unidade de tempo "insere a história não como processo, mas como fatalidade irreversível e imutável" (UBERSFELD, 1977 apudPAVIS, 2008, p. 422).

Com base nas definições de drama clássico, bem como nas considerações anteriores sobre a escola, não fica difícil relacionar alguns dos aspectos do contexto escolar com elementos do teatro dramático, visto que aquele, como invenção moderna, tende à padronização, pela qual se evidenciam tentativas de unificação de tempos, espaços e modos de existência. Todavia, seria a escola um espaço dramático fadado somente às tentativas de uniformização como uma fatalidade dramática, irreversível e imutável? Quais outras possibilidades de fabricação de saberes e produção de diferença atravessam o contexto escolar? Como engendrar movimentos de resistência a esse drama de imitação de padrões e motivador, portanto, de mecanizações e repetições?

Para delinear possíveis caminhos de investigação para as questões referidas, torna-se necessário, ainda, esboçar algumas ideias acerca do teatro contemporâneo. De acordo com Ryngaert, o teatro contemporâneo rompe com o modelo aristotélico e renuncia com os princípios de organização da exposição, conflito e desfecho, propondo estruturas dramatúrgicas mais fragmentadas e abertas (RYNGAERT, 2013). Notadamente influenciado pelo Teatro Épico, elaborado pelo encenador Bertold Brecht, tal rompimento tem seu início com a vanguarda dos anos 1950 e o Teatro do Absurdo, do qual se destacam as figuras dos dramaturgos Eugène lonesco e Samuel Beckett.

Ryngaert refere que o teatro contemporâneo estabelece outras relações com a narrativa da escrita teatral. Assiste-se, assim, a partir da segunda metade do século XX, a uma derrocada dos padrões de narrativa tradicional, unificadoras e carregadas de sentido. Segundo o autor, "Brecht impôs formas épicas radicais" e Beckett estabeleceu à narrativa tradicional um "regime emagrecedor, impiedoso a ponto de fazer pesar a ameaça permanente do silêncio definitivo”. (RYNGAERT, 2013, p. 83).

As rupturas estabelecidas pelo teatro contemporâneo apresentam estreitas relações com o que Lyotard chama de "condição pós-moderna". Esta, para o autor, caracteriza-se como uma posição de saber que "designa o estado da cultura após as transformações que afetaram as regras dos jogos da ciência, da literatura e das artes a partir da segunda metade do século XX" (LYOTARD, 2009, p. XV). As transformações apontadas estão ligadas à crise das noções de razão, sujeito, totalidade, verdade e progresso, sobretudo, à crise da noção de ordem, dispositivo central de legitimação do pensamento moderno (LYOTARD, 2009). A condição pós-moderna aponta, por conseguinte, para a noção de desordem e retomada da ideia de acontecimento como possibilidade de existência no estado de cultura pós-moderno.

É nesse contexto que Hans-Thies Lehmann cunha o termo pós-dramático (LEHMANN, 2017) a fim de descrever estéticas e estilos da prática teatral, desde "apresentações des-dramatizadas de textos dramáticos até formas que não dependem de modo algum de um texto-dramático pré-definido" (LEHMMAN, 2013, p. 860). Marcado pela presença da performance, o teatro pós-dramático aponta para a expansão das "possibilidades, tecnologias e estéticas da prática teatral" (LEHMANN, 2013, p. 872). Propõe uma ruptura com o conceito Aristotélico de unidade e totalidade do texto dramático e caracteriza-se pela ideia de desconstrução. No entanto, conforme nos alerta Lehmann, os elementos que constituem o teatro pós-dramático não se restringem a ruptura com o texto (LEHMANN, 2013). É 
possível trabalhar na perspectiva pós-dramática sem negar o texto dramático, o que muda é o lugar que ele ocupa na encenação.

O teatro pós-dramático desconstrói certa noção de ordem e aponta para uma reconfiguração dos papeis tanto do texto dramático na cena quanto das relações entre autor (do texto dramático), ator, expectador, diretor e do próprio espaço de encenação. Inserido na perspectiva do teatro contemporâneo, o teatro pós-dramático, segundo Lehmann, explora práticas que compõem um panorama de processos colaborativos na perspectiva de criação coletiva (LEHMANN, 2017).

Portanto, com o intuito de pensar a criação teatral como acontecimento que pretende desconstruir e, de certa maneira, desdramatizar as noções (vistas aqui como dramáticas) de totalidade, padronização e uniformização na aula, busca-se a construção de encontros educacionais que instaurem pequenos movimentos de resistência à ideia de que os alunos de uma classe corresponderiam a sujeitos de uma totalidade bem ordenada fadada ao destino imutável do bem aprender. Para isso, cria-se uma metodologia singularizada, a partir do deslocamento do conceito de pós-dramático para o contexto investigado, a qual denominamos pós-dramaturgia do encontro.

\section{OPERADOR METODOLÓGICO}

A partir das ideias de Deleuze e Guattari, no que tange à proposta de pensar a aula como um plano de composição e como um processo que não analisa ou reflete sobre determinada realidade, mas a inventa, este estudo experimenta a criação de uma metodologia singularizada como dispositivo para operar os movimentos da pesquisa (DELEUZE; GUATTARI, 2010). Tal invenção é engendrada a partir do deslocamento do conceito de pós-dramático para o contexto estudado, com o objetivo de problematizar a aula como espaço de dramaturgia, sendo o deslocamento dos corpos que a concebem pensados como texto e escritura teatral.

Neste panorama, a investigação articula-se com o conceito de dramaturgia, conforme pensado por Barba e Savarese, para os quais a palavra texto, antes de se referir a um texto escrito ou falado, impresso ou manuscrito, significa tecendo junto (BARBA; SAVARESE, 1995, p 68). Para os autores, não há, nesse sentido, representação que não tenha texto. Na perspectiva contemporânea, aponta Barba para uma pluralidade de dramaturgias que compõem o trabalho de criação em teatro: dramaturgias do ator, do diretor, do espectador, do espaço, sonora, entre outras (BARBA, 2014). Tais ideias contribuem para o deslocamento do conceito de dramaturgia para o contexto de pesquisa, visto que esta pensa também os corpos na aula como texto e seus deslocamentos como tecedura e escritura teatral.

Da mesma maneira que o pós-dramático desconstrói a hierarquia do texto dramático sobre os demais elementos da encenação, a metodologia pós-dramatizada proposta aqui problematiza as hierarquias entre professor e aluno, bem como possibilita a experimentação de ensaios para a invenção de uma docência "amodelar" (CORAZZA, 2013), uma vez que propõe procedimentos singularizados para a criação de encontros na aula. Pretende-se, com isso, experimentar modos de ser docente que movimentem rupturas e desvios das relações hierarquizadas dos processos educativos. É nessa ótica que este estudo desloca o termo pós-dramático do âmbito da cena contemporânea e o 
insere no contexto investigado não somente como possibilidade de atuação e pesquisa docente, mas também como dispositivo de invenção de teatralidades na aula.

A respeito das práticas teatrais no contexto pós-dramático, alude Lehmann que seus novos desdobramentos são marcados "por uma mudança de ênfase do gênio individual em primeiro plano para o trabalho colaborativo ou em grupo dentro e fora das instituições" (LEHMANN, 2013, p. 862). Esse é um dos aspectos com os quais a pós-dramaturgia do encontro se ocupa: investigar a aula como processo que desloca a figura do professor de gênio ou "principal detentor" de saberes para a experimentação de encontros constituídos em espaços-tempos de invenção coletiva.

\section{ENSAIOS PARA UMA PÓS-DRAMATURGIA DO ENCONTRO NA AULA}

Os fragmentos que seguem são trechos de duas aulas de teatro realizadas com uma turma de vinte e quatro alunos de sexto ano do Ensino Fundamental ${ }^{3}$. Ambos fizeram parte de um processo de criação teatral que utilizou uma adaptação do texto dramático "Sonhos de uma noite de verão", de William Shakespeare (SHAKESPEARE, 2014) como disparador para a criação teatral e invenção de corporeidades como saberes na aula de teatro. O texto tem como cenário a cidade de Atenas e apresenta um enredo no qual se interligam personagens e situações em três planos de ação. A peça do dramaturgo entrelaça a história de casais de enamorados, submetidos ao poder de um duque, com um grupo de artesãos, que também são atores amadores, e acontecimentos inesperados em uma floresta encantada, onde vivem elfos, duendes, fadas, entre outros seres fantásticos.

$\mathrm{Na}$ trama, amores são desfeitos e refeitos por influência de poções mágicas, traições e disputas de poder são vivenciadas; confusões e encantamentos fazem a rainha das fadas apaixonar-se por um homem com cabeça de burro, ao mesmo tempo em que uma peça de teatro é ensaiada, provocando riso, encontros inusitados e muita confusão. O texto possibilita, entre outros aspectos, problematizar relações de poder, nas quais as temáticas de gênero e controle patriarcal são experimentadas enquanto se traçam desvios, linhas de fuga e resistência a tais poderes, em uma trama que se desenrola entre a realidade e a fantasia.

Tendo como livre inspiração as problematizações de Gilles Deleuze com relação aos procedimentos do encenador italiano Carmelo Bene, foram propostos movimentos de criação teatral objetivando traçar planos de composição na aula, com o intuito de criar condições para a invenção de teatralidades e devires na aula, em especial aqueles relacionados com a consciência de minoria (DELEUZE, 2010). Para isso, foi proposta a leitura e discussão do texto dramático, assim como movimentos de criação de corporeidades que problematizassem as relações de hierarquia no texto dramático para que, a partir da subtração de personagens e/ ou elementos de poder da peça, pudessem ser experimentadas teatralidades em devir minoritário, criadas em um plano de composição.

\section{FRAGMENTO 1}

\footnotetext{
${ }^{3}$ Os nomes dos participantes foram substituídos por nomes fictícios, a fim de preservar o sigilo da pesquisa.
} 
- Abaixo de mim só cachorro, Sora - diz Ana4.

A cena que se vê é de uma sala de aula na qual as classes estão dispostas em formato de semicírculo. Vê-se uma mulher e alguns meninos e meninas em pé, conversando. Há também os que estão sentados ou circulando e, ainda, um menino que desliza pela cadeira, passa por baixo da classe, fala uma palavra e, aparentemente alheio ao que se passa, pega um lápis e se põe a esboçar algo em uma folha de caderno (Fig. 1). Não fosse a folha pautada, o quadro de classe afixado em uma parede, as mochilas penduradas nas cadeiras e alguns lápis abandonados sobre as classes, pensar-se-ia, em primeira visada, tratar-se de uma arena de teatro em que atores ensaiam livremente palavras para um espetáculo. Eles discutem calorosamente as relações de hierarquia na escola, na aula e em suas vidas.

Figura 1: Marionete em folha pautada.

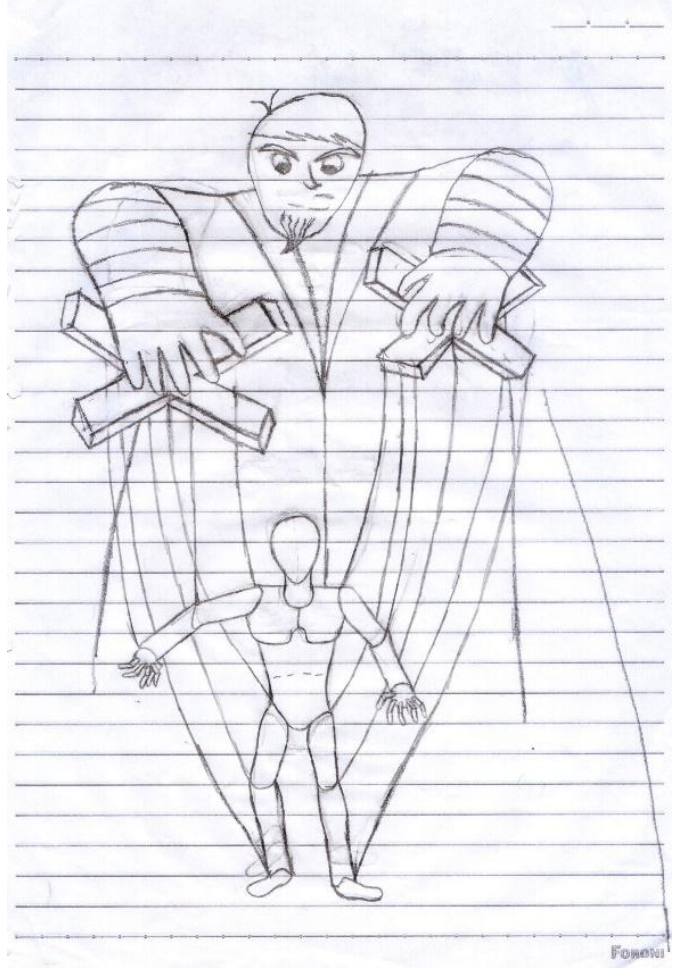

Fonte: Portfólio da pesquisadora.

Um observador que chegasse nesse instante, não imaginaria o quão confusa e barulhenta fora a preparação do cenário para esse momento. Uma preparação atravessada por uma profusão de movimentos, vozes, classes ruidosas e cadeiras caindo entre gritos de silêncio e pedidos de ordem proferidos pelos próprios alunos. Cenário caótico no qual uma professora, receosa de que o diretor viesse à sala reclamar do barulho, preparava-se para contar uma história de sonho, em uma noite de verão.

\footnotetext{
${ }^{4}$ Os trechos em itálico são descrições de fragmento de aulas, conforme coleta de dados realizada por meio de registros em diário de campo, bem como de filmagens e fotografias. Optou-se por um relato que entrelaça diálogos com trechos narrativos com o intuito de aproximá-lo a uma escrita mais dramatúrgica, compondo um texto cênico da aula, ao modo de alguns procedimentos do teatro pós-dramático, os quais optam por escrever o texto do espetáculo após (ou ao mesmo tempo) de sua criação em contexto coletivo.
} 
Entre os procedimentos abarcados na cena pós-dramática está a experimentação de espaços diferenciados para a encenação e, com isso, a construção de outras possibilidades de relação entre atores, expectadores e obra teatral. Lehmann, ao citar a montagem de Os Persas, de Claudia Bosse, afirma que "atores e público dividiam o mesmo espaço, movendo-se como um coro e de novo como protagonistas ao lado de espectadores que não se sentavam, mas permaneciam em pé ou circulavam pelo espaço" (LEHMANN, 2013, p. 867). Cabe salientar que a experiência referida é apenas um exemplo de uma gama de experimentações do teatro pós-dramático, as quais buscam romper de maneiras variadas com as perspectivas de frontalidade do palco italiano, sobretudo no que concerne à perspectiva de frontalidade da quarta parede 5 . Abre-se, assim sendo, um horizonte para a invenção de diferentes formas de relação com o dispositivo teatral que marcam, inclusive, um desmanchar de fronteiras entre o teatro e a performance.

O que se buscou com procedimento relatado foi constituir um acordo conjunto entre professora e alunos com respeito à intervenção no espaço, com o intuito de romper, a partir de um procedimento do pós-dramático, com a configuração de espacialidade daquela sala de aula. As classes, inicialmente, estavam dispostas em filas direcionadas para ao quadro de classe e, no ponto de vista proposto neste estudo, muito próximas da configuração de frontalidade do palco italiano, estimulando uma perspectiva de visão uniformizada, comum às instituições escolares modernas, as quais forjaram modos de articulação entre espaços, tempos e relação com o saber que tendiam à uniformização e mecanização de modos de ser na aula (CANÁRIO, 2005).

Conquanto a maioria das escolas ainda funcione à maneira das instituições modernas, não se pode ignorar que a pedagogia vem lançando novas propostas há algumas décadas. Segundo Sibilia, "tentou-se reformular todo o dispositivo sobre o qual se assentava a transmissão: a distribuição das carteiras na sala de aula, o redesenho do mobiliário e do espaço arquitetônico, até vocabulário relativo à situação de aprendizagem" (SIBILIA, 2012, p. 116). Convém ponderar que a reformulação espacial proposta no estudo não compactua com a ideia de pensar que a modificação do espaço por si só engendraria alguma transformação nos modos de ser e estar docente e discente na aula. O que se buscou com o procedimento apresentado foi promover uma ruptura com o que consideramos a forma canônica de disposição do espaço arquitetônico da sala de aula com o objetivo de desdramatizá-lo, de acordo com o operador metodológico da pesquisa, o qual denominamos pós-dramaturgia do encontro. Com o procedimento citado objetivou-se, portanto, convidar os personagens do encontro educacional a vivenciarem outras possibilidades de encontros e outras perspectivas de visão na (e da) aula.

Sobre as novas propostas que a pedagogia vem lançando, afirma Sibilia que:

assim, em lugar daquele que prescreve a verdade, teríamos algo bem mais modesto: um mediador ou articulador dos significados produzidos por todos, que circulam de modo mais ou menos igualitário na situação da aula, estimulando assim a construção conjunta de conhecimentos e protagonismo dos jovens nessa tarefa [...] no entanto, sem desmerecer suas boas intenções nem ignorar seus acertos, todos esses esforços e essas tentativas de reformular o dispositivo pedagógico não parecem ter ido suficientemente longe em sua contundência - ou não tiveram, até agora a eficácia buscada em seu reformismo radical do que acontece nas escolas. (SIBILIA, 2012, p. 117).

\footnotetext{
5 Termo cunhado por André Antoine para designar a parede imaginária à frente do palco e que o separa da plateia (VASCONCELLOS, 1987).
} 
A respeito das considerações da autora, é importante mencionar que a presente investigação não desloca o conceito de pós-dramático e o procedimento de criação coletiva da arte teatral para o campo da Educação com o intuito de engendrar um reformismo radical. Por outro lado, tampouco, compartilha a visão do professor como mediador da situação de aprendizagem, visto que a concepção de mediação reduz seu papel à figura de um comunicador, de alguém que apenas intermedia os processos educativos, e o que se busca nesse estudo é a experimentação de uma docência inventiva e, portanto, criadora.

Na perspectiva da pós-dramaturgia do encontro, o professor é aquele que inventa a aula junto com os alunos, compondo-a em processos colaborativos de criação. Para isso, estuda e prepara a sua aula efetuando "um trabalho preparatório, 'invisível, e silencioso, entretanto muito intenso' pelo qual o ato de dar aula é um a posteriori em relação a esse trabalho" (CORAZZA, 2012, p. 237). No caso da pós-dramaturgia do encontro, tal trabalho preparatório do professor consiste em pesquisar e elaborar dispositivos (como o texto dramático) dos quais extrai materialidades com o intuito de que sejam disparadoras do pensamento criador, evitando a aula "improdutiva, conservadora, obstaculizadora ou impeditiva da criação, da invenção, da fabricação do novo" (CORAZZA, 2012, p. 237).

A criação coletiva na aula de teatro seria, sob esse viés, um processo pelo qual o professor não é um mediador, mas habita uma zona de vizinhança com os alunos e constitui, no encontro educacional, corporeidades transversais em devir-criação, as quais nada mais são do que encontros com seus próprios pontos de subdesenvolvimento, seus patoás (DELEUZE; GUATTARI, 1977). Suas ações, portanto, não pretendem promover uma reforma radical do dispositivo pedagógico, mas experimentar movimentos singularizados que resistam às mecanizações que enfraquecem a vida de sua docência. Nesse panorama, a pós-dramaturgia do encontro compreende os movimentos, as desordens, os barulhos e ruídos, as vozes e os gritos da aula como a indisciplina necessária para que no caos se esboce um plano de composição, criação e resistência às mecanizações das práticas escolares (DELEUZE; GUATTARI, 2010).

\section{FRAGMENTO 2}

- Então, se não vivemos em um mundo com reis, rainhas, duques e condes, podemos mesmo assim identificar essas figuras de poder em nossas vidas? - pergunta a professora.

Ouve-se nesse momento um coro de vozes que exclama, sem hesitar:

-Sim!

Em seguida, algumas vozes se desgrudam do coro: citam os pais, a polícia, o presidente, $o$ prefeito e o professor como figuras de poder em suas vidas. Maria sussurra de maneira acanhada quase inaudivel:

-O diretor da escola.

A professora conta a história de "Sonho de uma noite de verão". Ao modo dramático, ela imagina que conseguirá ir do início ao meio e, deste, ao final da história. Não consegue. Descontentase, pois devido às conversas sobre o recreio, discussões paralelas e alguns corpos ruidosos que atravessam constantemente a arena da aula, não se escuta nada além de fragmentos de uma voz 
professoral. Os alunos desejam encenar a peça de Shakespeare. A professora gosta da ideia e, já mais satisfeita, lança seu melhor trunfo (acredita ela) para a aula: encenar a peça subtraindo dela algumas figuras ou elementos poder. Os alunos dizem não. Ela insiste. Eles também. Ela vibra em vontade de poder. Eles vibram em vontade de potência. Ela cede, enfim.

- Como um duque caminha? - pergunta a professora.

- Como o diretor da escola - responde Joana.

O que se vê em seguida é uma aula em que um plano de composição se traça nas construções coletivas, erigindo teatralidades forjadas em vozes e corpos que produzem movimentos que debocham e brincam com as hierarquizações. A aula, nesse instante, já não é mecanizada porque fabrica corporeidades e saberes embriagados de riso, som e vida.

O fragmento de aula citado põe em evidência dois aspectos problematizados pela pósdramaturgia do encontro. O primeiro deles relaciona-se com a necessidade de ruptura com a ideia de que existiria a maneira correta de dar uma aula. Nesse âmbito, assim como o teatro pós-dramático rompe com o modelo Aristotélico da dramaturgia clássica e da peça bem-feita e, com isso, com os princípios de exposição, conflito e desfecho (RYNGAERT, 2013), a pós-dramaturgia do encontro busca produzir fissuras na ideia de aula bem-feita comum aos dispositivos escolares modernos (SIBILIA, 2013). Renuncia, assim, à pretensão de que uma história deve ser contada com começo, meio e fim e, na experimentação de uma docência artista, cede às forças intensivas das vontades de potência. A pós-dramaturgia do encontro, portanto, singulariza o encontro educacional ao acolher os sons, ruídos e barulhos como composições que recortam o acontecimento pedagógico, propondo estruturas mais abertas e, quiçá, instaurando uma poética do fragmento na aula de teatro.

O segundo aspecto refere-se ao fato de que a pós-dramaturgia do encontro não é um procedimento que possa ser erigido de uma vez por todas, mas opera pela instauração de "linhas de fuga ou de variação contínua" (DELEUZE, 2010, p. 45). Inspirada nos procedimentos do teatro pósdramático (LEHMANN, 2013), desloca a figura do professor como gênio individual da experiência pedagógica quando o coloca em zonas de incerteza e errância. A pós-dramaturgia do encontro produziu, na situação vivenciada, uma corporeidade docente em devir-minoria em relação a modelos de docência totalitária e repleta de certezas sobre como deve ser uma aula.

Para Deleuze, "a subordinação do sujeito à intensidade ou ao afeto, à variação intensiva dos afetos" é um dos objetivos essenciais da arte (DELEUZE, 2010, p. 50). Já Sandra Corazza, no âmbito da constituição de uma docência artista, diz que os dados sobre a vontade de poder "indicam a favor de quem e do quê é realizado o confronto de forças na aula" (CORAZZA, 2012, p. 236). O fragmento estudado nos conduz a pensar que, quando a professora compartilhou da escolha dos alunos em não subtrair os elementos de poder na criação da cena teatral, subordinou e, de certa forma, desmanchou sua condição de sujeito (erigida na vontade de poder) a favor do afeto e das forças intensivas das corporeidades discentes da sala. Nesse ponto de vista, em que pese o procedimento de subtração não ter acontecido conforme planejado pela professora, a vontade de potência dos alunos forjou a subtração de uma figura de poder na aula: o poder professoral. Figura subtraída ao mesmo tempo em que as corporeidades discentes se ergueram, elas também, em devir minoritário. $\mathrm{Na}$ experiência apresentada, o teatro constituiu-se na aula como um aparato que 
não representa nada, mas apresenta e constitui uma consciência de minoria, enquanto deviruniversal, operando alianças aqui ou ali conforme o caso, seguindo linhas de transformação que saltam para fora do teatro e assumem uma outra forma, ou se reconvertem em teatro para um novo salto. Trata-se de uma tomada de consciência, embora ela nada tenha a ver com a consciência política marxista ou brechtiana. A consciência, a tomada de consciência, é uma grande potência. (DELEUZE, 2012, p. 64).

Essa tomada de consciência foi traçada em planos de composição, tornando possível a invenção de teatralidades que estabeleceram qualidades de relações diferenciadas entre si, com os objetos, sons, ruídos, caos e vazios da aula de teatro. Corporeidades inventivas da aula em devir cena, da cena em devir aula, do drama em devir pós-drama, de visões em devir encontro, invocando no conceito de devir zonas objetivas de "indeterminação e incerteza, comum e indiscernível; sobre a qual não se pode dizer onde passam as fronteiras de uns e de outros" (CORAZZA, 2013, p. 26), já que conforme Deleuze e Guattari, "não estamos no mundo, tornamo-nos com o mundo, nós nos tornamos, contemplando-o. Tudo é visão. Tornamo-nos universo. Devires animal, vegetal, molecular, devir zero" (DELEUZE; GUATTARI, 2010, p. 200).

Figura 2: Corpo em devir mesa ou mesa em devir palco.

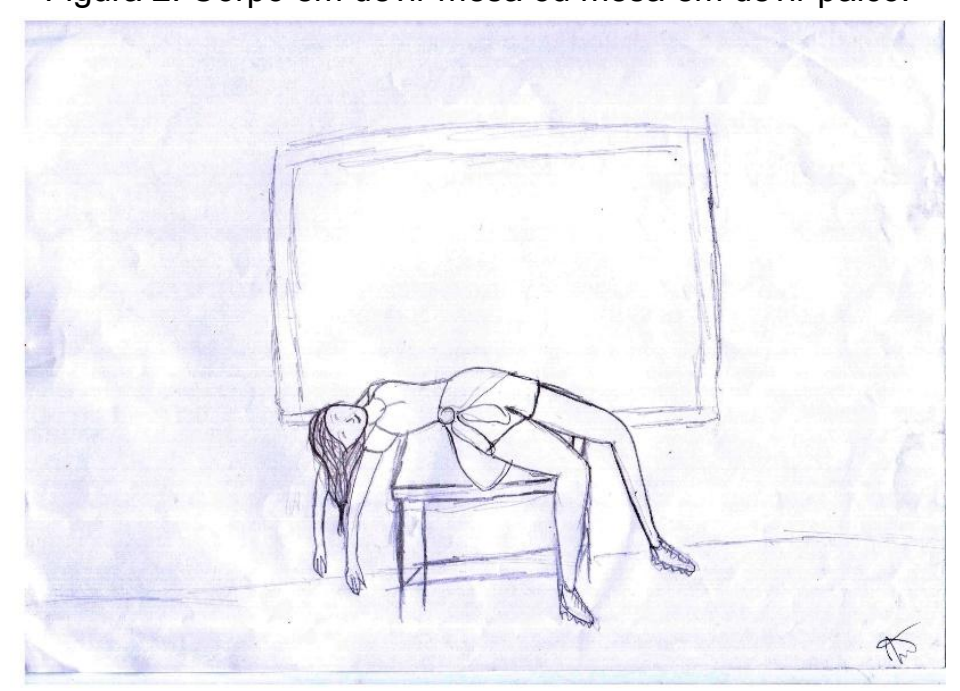

Fonte: Portfólio da pesquisadora.

A pós-dramaturgia do encontro, assim, não aprende sobre, nem ensina para, mas cria junto, inventa com as corporeidades da aula e o faz com vistas à produção de pensamentos sem certezas do que seja o bem aprender ou bem ensinar, perguntando-se a todo o momento: Que encontros uma aula produz? Quais teatralidades em devir ela inventa? Como o pensamento criador resiste às mecanizações e "reivindica o movimento do infinito" (DELEUZE, 2010, p. 47) na aula?

\section{CONSIDERAÇÕES FINAIS}

A investigação coloca em cena a aula de teatro no contexto da educação básica e discute perspectivas de resistência à mecanização das práticas escolares. Desse procedimento resulta a invenção de uma metodologia singularizada como operadora dos movimentos da pesquisa. Extrai-se, consequentemente, do conceito de teatro pós-dramático aspectos geradores para outros modos de pensar a criação teatral no contexto investigado, na perspectiva de desconstrução e produção de 
variações na aula. Estas resistem às padronizações e uniformizações do espaço escolar e experimentam relações com o saber teatral, colocando-o mais como invenção de corporeidades e sensações traçadas em um plano de composição, do que como comunicação ou descoberta de realidades.

A pesquisa discute também a criação coletiva no âmbito da educação escolarizada e, ao fazêlo, questiona certa noção de ordenamento dos tempos e espaços na escola, reguladores de maneiras de ser e estar nesse contexto. Aponta, assim, para a experimentação de modos de ser docente e discente que colocam em questão o modelo de professor como detentor do conhecimento e, portanto, de poder, abrindo possibilidades para a composição de teatralidades e produção de devires (DELEUZE, 2010) na aula.

A investigação considera que o teatro pode atuar no contexto estudado como prática de criação coletiva, na qual os papéis dos seres animados (professores, alunos), bem como dos seres inanimados (mesas, cadeiras, texto dramático) são reconfigurados com o intuito de fabricar dramaturgias, devires de consciência minoritária (DELEUZE, 2010) e potências de vida na aula. Conclui que os movimentos de resistência experimentados não acontecem o tempo todo, nem se estabelecem de uma vez por todas, mas se constituem em deslocamentos, instantes de escape ou linhas de fuga (DELEUZE; GUATTARI, 2010), as quais acontecem a partir da busca de singularização dos encontros pedagógicos e suas configurações (sempre temporárias), ensaiando caminhos para a instauração de uma pósdramaturgia do encontro na aula de teatro.

\section{REFERÊNCIAS}

1. BARBA, Eugenio; SAVARESE, Nicola. A Arte Secreta do Ator. Trad. Luís Otávio Burnier. Campinas: Editora da Unicamp/Hucitec, 1995. Queimar a casa: origens de um diretor. Trad. Patrícia Furtado Mendonça. São Paulo: Perspectiva, 2014.

3. CANÁRIO, Rui. O que é a escola? Um “olhar” sociológico. Porto: Porto Editora, 2005.

4. CORAZZA, Sandra Mara. Didaticário de criação: aula cheia, antes da aula. In: XVI ENDIPE ENCONTRO NACIONAL DE DIDÁTICAS E PRÁTICAS DE ENSINO, 2012. Campinas: Junqueira\&Marin Editores, p. 235-241. O que se transcria em educação? Porto Alegre: UFRGS, Doisa, 2013

6. DELEUZE, Gilles; GUATTARI, Félix. O que é a filosofia? 3. ed. Trad. Bento Prado Jr. e Alberto Alonso Muñoz. São Paulo: Ed. 34, 2010. 

Sobre o teatro: Um manifesto a menos; O esgotado. Trad. Fátima Saadi, Ovídio de Abreu, Roberto Machado. Rio de Janeiro: Zahar, 2010.

9. FERREIRA, Aurélio Buarque de Holanda. Novo Dicionário da Língua Portuguesa. 2. ed. Rio de Janeiro: Editora Nova Fronteira S.A.,1986.

10. GALLO, Silvio. De la anarquiología como oporeador metodológico. In: CORTÉS, Oscar Pulido e BERNAL, Orlando Espinel Bernal (coord.). Formas y expresiones metodológicas em el último Foucault. Tunja: UPTC, 2017.

11. LEHMANN, Hans-Thies. Teatro Pós-Dramático. Trad. Manuela Gomes, Sara Seruya. Lisboa: Orfeu Negro, 2017. Teatro Pós-Dramático, doze anos depois. Rev. Bras. Estud. Presença, Porto Alegre: UFRGS, v.3, n.3, p. 859-878, set/dez. 2013. ISSN 2237-2660. Disponível em: https://www.seer.ufrgs.br/presenca. Acesso em: 01 ago. 2019.

14. PAVIS, Patrice. Dicionário de teatro. Trad. sob a direção de J. Guinsburg, Maria Lúcia Pereira. São Paulo: Perspectiva, 2008.

15. RYNGAERT, Jean-Pierre. Ler o teatro contemporâneo. 2. ed. Trad. Andréa Stahel M. da Silva. São Paulo: Editora WMF Martins Fontes, 2013.

16. SHAKESPEARE, Willian. Sonhos de uma noite de verão. Adaptação de Barbara Kindermann. Ilustração de Almud Kunert. Tradução de Christine Röhrig. São Paulo: Cereja Editora, 2014.

17. SIBILIA, Paula. Redes ou paredes: a escola em tempos de dispersão. Trad. Vera Ribeiro. Rio de Janeiro: Contraponto, 2012.

18. VASCONCELOS, Luiz Paulo. Dicionário de Teatro. Porto Alegre: L\&PM, 1987.

\section{Fabíola Rahde Fernandes}

Mestra em Educação pela Universidade Estadual do Rio Grande do Sul - UERGS. Professora de Arte na Prefeitura Municipal de Xangri-Lá/RS. 


\section{Eduardo Guedes Pacheco}

Doutor em Filosofias da Diferença e da Educação pela Universidade Federal do Rio Grande do Sul UFRGS. Professor Titular da Universidade Estadual do Rio Grande do Sul - UERGS. Coordenador do Programa de Mestrado Profissional em Educação da Universidade Estadual do Rio Grande do Sul UERGS.

Como citar este documento:

FERNANDES, Fabíola Rahde; PACHECO, Eduardo Guedes. Educação, Teatro e Invenção: ensaio para uma Pós-Dramaturgia do encontro na aula. Reflexão e Ação, Santa Cruz do Sul, v. 28, n. 2, jun. 2020.

ISSN 1982-9949.

Disponível

em:

$<$ https://online.unisc.br/seer/index.php/reflex/article/view/14230>. Acesso em: doi:https://doi.org/10.17058/rea.v28i2.14230. 